4. Weisskopf, M. G., Castillo, P. E., Zalutsky, R. A. \& Nicoll, R. A. Mediation of hippocampal mossy fiber long-term potentiation by cyclic AMP. Science 265, 1878-1882 (1994).

5. Huang, Y-Y., Li, X.-C. \& Kandel, E. cAMP contributes to mossy fiber LTP by initiating both a covalently mediated early phase and macromolecular synthesis-dependent late phase. Cell 79, 69-79 (1994).

6. Huang, Y. Y. et al. A genetic test of the effects of mutations in PKA on mossy fiber LTP and its relation to spatial and contextual learning. Cell 83, 1211-1222 (1995).

Zalutsky, R. A. \& Nicoll, R. A. Comparison of two forms of long-term potentiation in single hippocampal neurons. Science 248, 1619-1624 (1990).

8. Weisskopf, M. G. \& Nicoll, R. A. Presynaptic changes during mossy fiber LTP revealed by NMDA receptor-mediated synaptic responses. Nature 376, 256-259 (1995).

9. López-Garcia, J. C., Arancio, O., Kandel, E. R. \& Baranes, D. A presynaptic locus for long-term potentiation of elementary synaptic transmission at mossy fiber synapses in culture. Proc. Natl Acad. Sci. USA 93, 4712-4717 (1996).

10. Xiang, Z., Greenwood, A. C., Kairiss, E. W. \& Brown, T. H. Quantal mechanism of long-term potentiation in hippocampal mossy-fiber synapses. J. Neurophysiol. 71, 2552-2556 (1994).

11. Ferro-Novick, S. \& Jahn, R. Vesicle fusion from yeast to man. Nature 370, 191-193 (1994).

12. Bennett, M. K. \& Scheller, R. H. A molecular description of synaptic vesicle membrane trafficking. Annu. Rev. Biochem. 63, 63-100 (1994).

13. Südhof, T. C. The synaptic vesicle cycle: a cascade of protein-protein interactions. Nature 375, 645653 (1995).

14. DeCamilli, P., Benfenati, F., Valtorta, F. \& Greengard, P. The synapsins. Annu. Rev. Cell Biol. 6, $433-$ 460 (1990)

15. Spillane, D. M., Rosahl, T. W., Südhof, T. C. \& Malenka, R. C. Long-term potentiation in mice lacking synapsins. Neuropharmacology 34, 1573-1579 (1995).

16. Fykse, E. M., Li, C. \& Südhof, T. C. Phosphorylation of rabphilin-3A by $\mathrm{Ca}^{2+} / \mathrm{calmodulin-}$ and cAMPdependent protein kinases in vitro. J. Neurosci. 15, 2385-2395 (1995).

17. Wang, Y., Okamoto, M., Schmitz, F., Hofmann, K. \& Südhof, T. C. Rim is a putative Rab3 effector in regulating synaptic-vesicle fusion. Nature 387, 000-000 (1997)

18. Geppert, M. et al. The role of Rab3A in neurotransmitter release. Nature 369, 493-497 (1994).

19. Rosahl, T. W. et al. Essential functions of synapsins I and II in synaptic vesicle regulation. Nature 375, 488-493 (1995)

20. Fykse, E. M. et al. Relative properties and localizations of synaptic vesicle protein isoforms: the case of the synaptophysins. J. Neurosci. 13, 4997-5007 (1993).

21. Kamiya, H., Shinozaki, H. \& Yamamoto, C. Activation of metabotropic glutamate receptor type $2 / 3$ suppresses transmission at rat hippocampal mossy fibre synapses. J. Physiol. (Lond.) 493, 447-455 (1996)

22. Yokoi, M. et al. Impairment of hippocampal mossy fiber LTD in mice lacking mGluR2. Science $\mathbf{2 7 3}$ 645-647 (1996)

23. Zucker, R. S. Short-term synaptic plasticity. Annu. Rev. Neurosci. 12, 13-31 (1989).

24. Geppert, M., Goda, Y., Stevens, C. F. \& Südhof, T. C. Rab3A regulates a late step in synaptic vesicle fusion. Nature 387, 810-814 (1997).

25. Regehr, W. G., Delaney, K. R. \& Tank, D. W. The role of presynaptic calcium in short-term enhancement at the hippocampal mossy fiber synapse. J. Neurosci. 14, 523-537 (1994).

26. Salin, P. A., Scanziani, M., Malenka, R. C. \& Nicoll, R. A. Distinct short-term plasticity at two excitatory synapses in the hippocampus. Proc. Natl Acad. Sci. USA 93, 13304-13309 (1996).

27. Seamon, K. B. \& Daly, J. W. Forskolin: Its biological and chemical properties. Adv. Cyclic Nucleot. Prot. Phosphoryl. Res. 20, 1-150 (1986)

28. Dixon, D. \& Atwood, L. Adenylate cyclase system is essential for long-term facilitation at the crayfish neuromuscular junction. $J$. Neurosci. 9, 4246-4252 (1989).

29. Schacher, S., Castellucci, V. F. \& Kandel, E. R. cAMP evokes long-term facilitation in Aplysia sensory neurons that requires new protein synthesis. Science 240, 1667-1669 (1988).

30. Li, C. et al. Synaptic targeting of rabphilin-3A, a synaptic vesicle $\mathrm{Ca}^{2+} /$ phospholipid-binding protein depends on rab3A/3C Neuron 13,885-898 (1994).

Acknowledgements. We thank H. Czerwonka for secretarial assistance. R.A.N. is a member of the Keck Center for Integrative Neuroscience and the Silvio Conte Center for Neuroscience Research. R.C.M. is member of the Center for Neurobiology and Psychiatry, and the Center for the Neurobiology of Addiction. R.A.N. and R.C.M. are supported by grants from the NIH. T.C.S. was supported by grants from the HFJP and the W.M. Keck Foundation. R.J. was supported by a postdoctoral fellowship from DFG.

Correspondence and requests for materials should be addressed to R.A.N. (e-mail: nicoll@phy.ucsf.edu).

\section{Rim is a putative Rab3 effector in regulating synaptic-vesicle fusion}

\section{Yun Wang ${ }^{\star}$, Masaya Okamoto*, Frank Schmitz $\dagger$ Kay Hofmann $\ddagger$ \& Thomas C. Südhof*}

* Department of Molecular Genetics and Howard Hughes Medical Institute, The University of Texas, Southwestern Medical Center at Dallas, Texas 75235 , USA

$\dagger$ Abteilung IX, Max-Planck-Institut für Experimentelle Medizin, 37075 Göttingen, Germany

$\ddagger$ Swiss Institute for Experimental Cancer Research, 1066 Epalinges, Switzerland

Rab3 is a neuronal GTP-binding protein that regulates fusion of synaptic vesicles and is essential for long-term potentiation of hippocampal mossy fibre synapses ${ }^{1-5}$. More than thirty Rab GTPbinding proteins are known to function in diverse membrane transport pathways, although their mechanisms of action are unclear. We have now identified a putative Rab3-effector protein called Rim. Rim is composed of an amino-terminal zinc-finger motif and carboxy-terminal PDZ and $\mathrm{C}_{2}$ domains. It binds only to GTP (but not to GDP)-complexed Rab3, and interacts with no other Rab protein tested. There is enrichment of Rab3 and Rim in neurons, where they have complementary distributions. Rab3 is found only on synaptic vesicles, whereas Rim is localized to presynaptic active zones in conventional synapses, and to presynaptic ribbons in ribbon synapses. Transfection of PC12 cells with the amino-terminal domains of Rim greatly enhances regulated exocytosis in a Rab3-dependent manner. We propose that Rim serves as a Rab3-dependent regulator of synaptic-vesicle fusion by forming a GTP-dependent complex between synaptic plasma membranes and docked synaptic vesicles.

Rab3A and Rab3C are small GTP-binding proteins of synaptic vesicles that cycle between vesicle-associated, GTP-complexed forms and cytosolic, GDP-complexed forms as a function of exocytosis $^{6-8}$. Deletion of Rab3A in mice enhances neurotransmitter release without changing the docking or priming of synaptic vesicles, suggesting that Rab3 has a role in regulating synapticvesicle fusion ${ }^{4}$. Rab3A is also required for long-term potentiation (LTP) of synaptic transmission in mossy fibre synapses of the hippocampus, indicating that Rab3 physiologically regulates the extent of synaptic-vesicle fusion in synaptic plasticity ${ }^{5}$. Rab3 and other Rab proteins are thought to function by GTP-dependent interactions with effector proteins ${ }^{8-10}$, although the number and nature of these effectors are unknown: only a few candidate effectors have been described for more than thirty Rab proteins, including rabphilin- $3 \mathrm{~A}^{11}$. Rabphilin is colocalized with Rab3 on synaptic vesicles, and binds to Rab3 as a function of GTP by means of an $\mathrm{N}$-terminal zinc-finger domain ${ }^{12,13}$. However, rabphilin on its own seems insufficient to account for the actions of Rab3, and so Rab3 could have multiple effectors.

By using an activating form of Rab3C fused to the DNA-binding domain of LexA as a bait, we screened a rat brain cDNA library by yeast two-hybrid selection for proteins that interact with Rab3. Positive prey clones were rescued and retransformed into fresh yeast cells with Rab3 baits or control baits. We then evaluated the specificity of the prey and bait interactions by using two assays for transactivation, namely $\beta$-galactosidase induction and histidine autotrophy ${ }^{14}$. In this way we identified a class of prey clones that interact only with Rab3 in the yeast two-hybrid system, and encode part of a new protein called Rim (for Rab3-interacting molecule). Northern blots revealed that Rim mRNA is only detectable in brain (data not shown), suggesting that Rim is a candidate neuronal effector for the synaptic actions of Rab3.

We obtained only partial Rim cDNA clones in the yeast twohybrid screens, so we isolated full-length cDNA clones from rat brain libraries. Their sequences showed that Rim is a large protein (1,553 amino acids) with several alternatively spliced variants (Fig. 1). We observed variable sequences in multiple independent cDNA clones at three positions. Two of these alternatively spliced sequences occur in three distinct variants, suggesting that Rim can be present in up to 18 forms. Databank searches identified a Rim homologue in Caenohhabditis elegans that is distributed over two cosmid sequences (T10A3 and K03A1). Because rabphilin is also present in C. elegans, both putative effectors for Rab3 are evolutionarily conserved. Analysis of the Rim sequence demonstrates that it is composed of multiple domains present in both the rat and C. elegans proteins: an N-terminal zinc-finger domain, a highly charged sequence followed by an alanine/proline-rich region, a PDZ domain, and $\mathrm{C}_{2}$ domains separated by alternatively spliced sequences (Fig. 1).

The Rab3-binding protein rabphilin also has a zinc-finger motif and two $\mathrm{C}_{2}$ domains. However, the zinc-fingers of Rim and rabphilin are only weakly homologous $(42 \%$ identity over 55 residues), and their $\mathrm{C}_{2}$ domains belong to different classes ${ }^{15}$. Furthermore, rabphilin lacks the other domains of Rim (the PDZ 
domain, alternatively spliced sequences, and alanine/proline-rich domain), making the two proteins quite different. The homologous zinc-fingers of Rim and rabphilin are found in their N-terminal Rab3-binding domains ${ }^{11-13}$ (Fig. 1). Rabphilin binds to Rab3 but not to other Rab proteins ${ }^{11-13}$, so we investigated whether Rim exhibits a similar Rab3-binding specificity.

We studied the interactions of the Rim prey and of a synaptotagmin control prey with wild-type and mutant forms of Rab3, Rab4, Rab5, Rab7, Rab17 and Rab22 by using yeast two-hybrid assays (Table 1). Most of the mutations locked the Rab proteins in either the GTP- or the GDP-bound states, and are referred to as activating and inactivating, respectively. We found that Rab3 bound to Rim, whereas the other Rab proteins were inactive (Table 1). Binding of wild-type Rab3A to Rim, as measured by $\beta$-galactosidase activation, was low. However, binding of Rab3A was greatly enhanced by independent activating mutations (such as Rab3A(Q81L) and Rab3A(S31V,S37P)). Corresponding mutations in other Rab proteins (such as Rab5(Q79L), Rab5(I53M) and Rab7(Q67L)) had no effect, even though the Rab5 mutants exhib- ited strong activation of $\beta$-galactosidase with rabaptin preys in the same assays (data not shown). Finally, an inactivating mutant of Rab3A that stabilizes its GDP-bound forms (Rab3A(T36N)) did not induce $\beta$-galactosidase above background levels (Table 1). To confirm that Rim interacts with only GTP-bound Rab3, we also studied it biochemically. Glutathione $S$-transferase (GST) fusion proteins of the $\mathrm{N}$ terminus of Rim containing the zinc-finger domain were immobilized on glutathione beads and incubated with solubilized brain proteins in the presence of GTP- $\gamma S$ or GDP- $\beta S$. Rab3A bound to immobilized GST-Rim only with GTP- $\gamma$ S (Fig. 1d); control GST proteins or the column matrix itself did not bind (data not shown), confirming the specificity of binding.

Thus Rim binds exclusively to Rab3 as a function of GTP by means of a zinc-finger-containing sequence. We investigated whether similar sequences are present in other potential Rabbinding proteins by searching databanks with reiterative profiles constructed from the rat and C. elegans Rim and rabphilin zincfinger sequences, and were able to identify a class of related zinc-

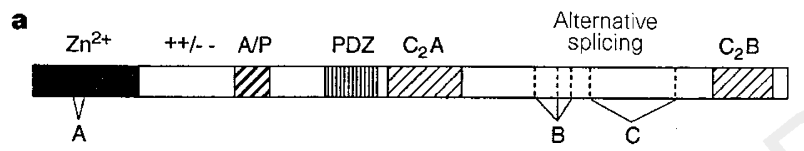

b

1 MSSAVGPRGPRPPTVPPPMQELPDLSHLTEEERNI IMAVMDRQKEEEEKEEAMLKCVVRD 61 MAKPAACKTPRNAESQPHQPPINIFRCYCYPRKPSSEEGGPERDFRL HQQFES YKEQVRK 121 IGEEARRYQGEHKDDAPTEGICHKTKFADGCGHLSYGRTKFCARCGGGVSLRSNNEDKV 181 VMWVGNL Y̌RKQQEILTKSGAWFFGSGPQQPSQDGTLSDTATGAGSEVPREKKARLQERSR 241 SQTPLSTAAVSSQDTATPGAPLHRNKGAEPSQQALGPEQKQASRSRSEPPRERKKAPGLS 301 EQNGKGGQKSERKRVPKSWVQPGEGIADERERKERRETRRLEKGRSQDYSDRPEKRDNG 361 VAEDQKQRKEEEYQTRYRSDPNLARYPVKAPPEEQQMRMHARVSRARHERRHSDVALPHT 421 EAAAAAPAEATAGKRAPATARVSPPESPRARAAAAQPPTEHGPPPPRPAPGPAEPPEPR 481 PEPLRKQGRLDPGSAVLLRKAKREKAESMLRNDSLSSDQSESVRPSPPKPHRPKRGGKRR 541 QMSVSSSEEEGVSTPEYTSCEDVELESESVSEKGDLDYYWLDPATWHSRETSPISSHPV 601 WQPSKEGDRLIGRVILNKRTTMPKESGALLGLKVVGGKMTDLGRLGAFITKVKKGSLADV 661 VGHLRAGDEVLEWNGKPLPGATNEEVYNIILESKSEPQVEIIVSRPIGDIPRIPESSHP 721 LESSSSSFESOKMERPSISVISPTSPGALKDAPOVLPGQLSVKLWYDKVGHQLIVNVLOA 781 TDLPPRVDGRPRNPYVKMYFLPDRSDKSKRRTKTVKKLLEPKWNOTFVYSHVHRRDFRER 841 MLEITVWDQPRVQDEESEFLGEILIELETALLDDEPHWYKLOTHDESSLPLPQPSPFMP 901 RHIBGESSSKKLORSORISDSDISDYEVDDGIGVVPPVGYRASARESKATTLTVPEOQR 961 THHRSRSVSPHRGDDQGRPRSRLPNVPLORSLDEIHPTRRSRSPTRHHDASRSPADHRSR 1021 HVESOYSSEPDSELLMLPRAKRGRSAESLHRTSELOPSLDRARSASTNCLRPDTSLHSP 1081 RERHSRRSERCSTOXOSRKGTASDADRTHRQGSPTQSPPADTSFGSRRGROLPQVPVRSC 1141 SIEOASLVVEERTROMKVKVHRFKOTTGSGSSOELDHEOYSKYNIHKDOYRSCDNASAKS 1201 SDSDVSDVSAISRASSTSRISSTSFMSEOSERPRGRISSFTPRMOGRRMGTSGRAIIRST 1261 SVSGEIYTLRRNDGSOSDTAVGTVGAGGKKRRSSLSAKVVAIVSRRSRSTSOISOTESG 1321 KKLKSTIORSTETGMAAEMRKMVRQPSRESTDGS INSYSSEGNLIFPGVRVGPDSOFSD 1381 LDGLGPAOLVGROTLATPAMGDIOIGMEDKKGOLEVEVIRARSLTOKPGSKSTPAPYVKV 1441 YLLENGACIAKKKTRIARKTLDPLYOOSLVFDESPOGKVIOVIVWGDYGRMDHKCFMGVA 1501 QIULEELDLSSMVIGWYKLFPPSSLVDPTLAPLTRRASOSSLFSSSGPPCIRS*

\section{$\mathrm{Zn}^{2+}$ $++1-$ A/P-rich domain PDZ domain $\mathrm{C}_{2} \mathrm{~A}$ domain spliced $\mathrm{C}_{2} \mathrm{~B}$ domain}

d

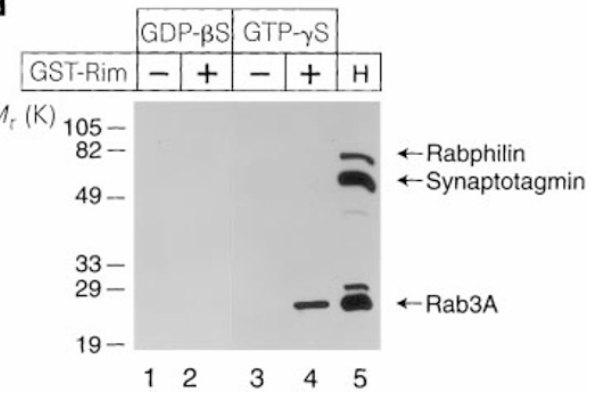

RIM

RIM
Rabph

Rabph
Rabph

FAB

FGD1

VACl/1

ZK632.12

T24A1I. 1

C33D9.1 Ce

DEA1 0.20

HRS

HRS

VPS 27

D1022.7

YGLO23C

c

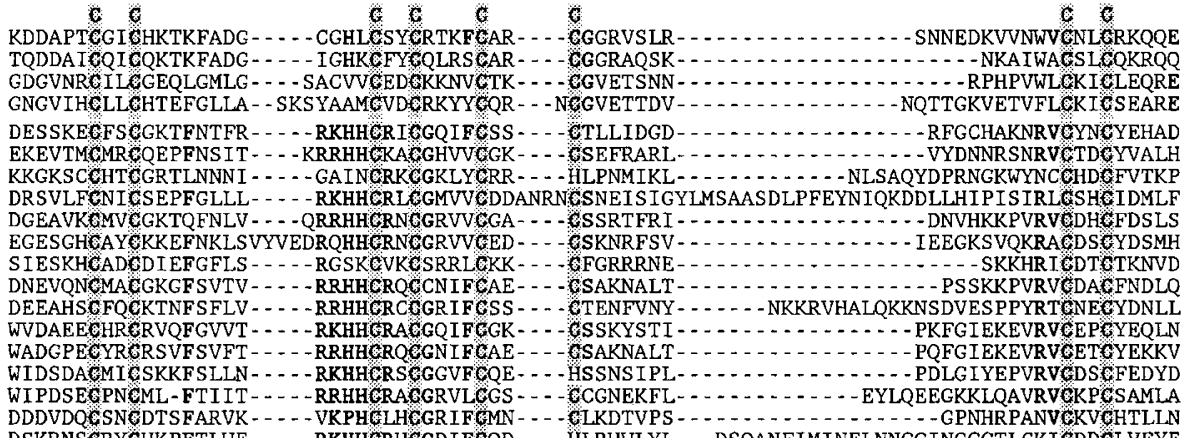

Figure 1 a, Domain structure of Rim. The following domains are marked: $\mathrm{Zn}^{2+}$, zinc-finger; ++/--, charged sequence (33\% charged amino acids in 186 residues); $A / P$, alanine/proline-rich sequence (57\% alanines and prolines over 69 amino acids); PDZ, PDZ domain; $C_{2} A$ and $C_{2} B$, first and second $C_{2}$ domains. $A, B$ and $C$, positions of alternative splicing. $\mathbf{b}$, Sequence of Rim. Domains are identified on the right. Alternatively spliced sequences are underlined. In addition to the fulllength sequences, variants lacking the following residues were observed: site $A$, 83-105 and 83-106; site B, 1032-1106 and 1083-1106; site C, 1145-1316. c, Alignment of sequences related to the zinc-finger domain of Rim. The rat and C. elegans Rim and rabphilin zinc-finger sequences are aligned with each other

and a set of zinc-finger sequences from GenBank that is characterized by a polybasic motif (R-R/K-H-H-C-R-X-C-G; see ref. 17). Conserved cysteine residues are shaded. Proteins are identified on the left. Species abbreviations: $\mathrm{Rn}$, rat; $\mathrm{Ce}$, C. elegans; Hs, human; Sc, Saccharomyces cerevisiae; Mm, mouse. d, GTPdependent binding of Rab3A to immobilized Rim. Rat brain homogenate (lane 5) was affinity chromatographed on a glutathione control column (lanes 1 and 3) or a glutathione column with immobilized GST-Rim containing the N-terminal zincfinger of Rim (lanes 2 and 4 ) in the presence of GDP- $\beta$ S or GTP- $\gamma$ S. Fractions were immunoblotted, with ECL detection. 
finger sequences with significant homology to the Rim/rabphilin zinc-finger (Fig. 1c). This class forms a separate subset of zincfingers that is present in proteins from yeast to mammals, some of which (Vac1, Fab1 and Hrs-2) function in membrane transport ${ }^{16-18}$. Statistical analysis showed that the probability that the different zinc-fingers in Fig. 1c are not related to each other is $P<0.06$. By contrast, no other zinc-finger domain reached scores of $P<0.50$. Therefore, the zinc-finger domains of Rim and Rabphilin define a zinc-finger motif present in multiple proteins, some of which may function physiologically as Rab targets in membrane transport.

\section{Table 1 Quantification of the interaction of Rim prey and Rab bait clones}

\begin{tabular}{|c|c|c|c|}
\hline Bait vector & pPreyRim-100 & pPreyRim-52 & pVP16-SytlC ${ }_{2} A / B$ \\
\hline pLexNRab3A & $37.2 \pm 3.9$ & $13.4 \pm 2.5$ & $9.7 \pm 4.8$ \\
\hline pLexNRab3 $^{T 36 N}$ & $5.2 \pm 2.8$ & $5.6 \pm 1.3$ & $4.5 \pm 2.3$ \\
\hline pLexNRab3A $^{\text {S31V,S37P }}$ & $513.2 \pm 16.7$ & $199.8 \pm 27.0$ & $3.2 \pm 1.7$ \\
\hline pLexNRab3A ${ }^{Q 81 L}$ & $601.6 \pm 15.4$ & $204.8 \pm 20.4$ & $5.0 \pm 2.6$ \\
\hline pLexNRab3A ${ }^{N 135 I}$ & $205.3 \pm 12.4$ & $55.6 \pm 7.8$ & $5.4 \pm 2.7$ \\
\hline pLexNRab3C* & $583.3 \pm 27.3$ & $1,068.8 \pm 16.6$ & $4.1 \pm 1.0$ \\
\hline pLexNRab4B & $6.7 \pm 3.2$ & $2.6 \pm 0.7$ & $2.9 \pm 0.6$ \\
\hline pLexNRab5 & $5.5 \pm 3.1$ & $4.3 \pm 0.8$ & $0.9 \pm 0.5$ \\
\hline pLexNRab5 $5^{\text {S34N }}$ & $6.4 \pm 3.6$ & $6.2 \pm 1.3$ & $4.2 \pm 2.4$ \\
\hline pLexNRab5 ${ }^{153 M}$ & $6.7 \pm 3.3$ & $7.2 \pm 1.7$ & $5.5 \pm 2.9$ \\
\hline pLexNRab5 ${ }^{Q 79 L}$ & $6.8 \pm 2.3$ & $6.4 \pm 3.3$ & $4.5 \pm 3.0$ \\
\hline pLexNRab7 & $4.1 \pm 2.5$ & $3.9 \pm 0.6$ & $6.5 \pm 3.2$ \\
\hline pLexNRab7 $7^{\mathrm{Q} 67 \mathrm{~L}}$ & $5.9 \pm 3.1$ & $3.4 \pm 0.7$ & $8.4 \pm 4.2$ \\
\hline pLexNRab17 & $4.0 \pm 2.7$ & $3.7 \pm 1.4$ & $4.8 \pm 2.8$ \\
\hline pLexNRab22 & $1.2 \pm 0.8$ & $2.2 \pm 1.2$ & $1.3 \pm 0.8$ \\
\hline
\end{tabular}

Results are obtained from yeast two-hybrid assays by transactivation of $\beta$-galactosidase activity. The two Rim prey vectors and the synaptotagmin 1 control prey vector (pVP16$\mathrm{Syt}_{\mathrm{C}} \mathrm{C}_{2} \mathrm{~A} / \mathrm{B}$ ) were co-transformed with the indicated bait vectors into yeast and plated on UTL plates. Single colonies were grown in liquid culture for $40 \mathrm{~h}$ before collection, and the $\beta$ galactosidase activity and protein content of each culture were determined. Data shown are mean \pm s.e.m. $\mathrm{nmol}$ per min and $\mathrm{mg}$ protein from triplicate determinations. The sequence of rate PLexNRab3C* exhibits 7 amino-acid changes compared to the bovine sequence ${ }^{30}$. Y17F, D24V, Q80R, V141A V1531, H160R and N121S. These probably represent evolutionary changes, except for the Q89R mutation, which corresponds to the critical glutamine residue that is mutated in Rab-activating mutations.

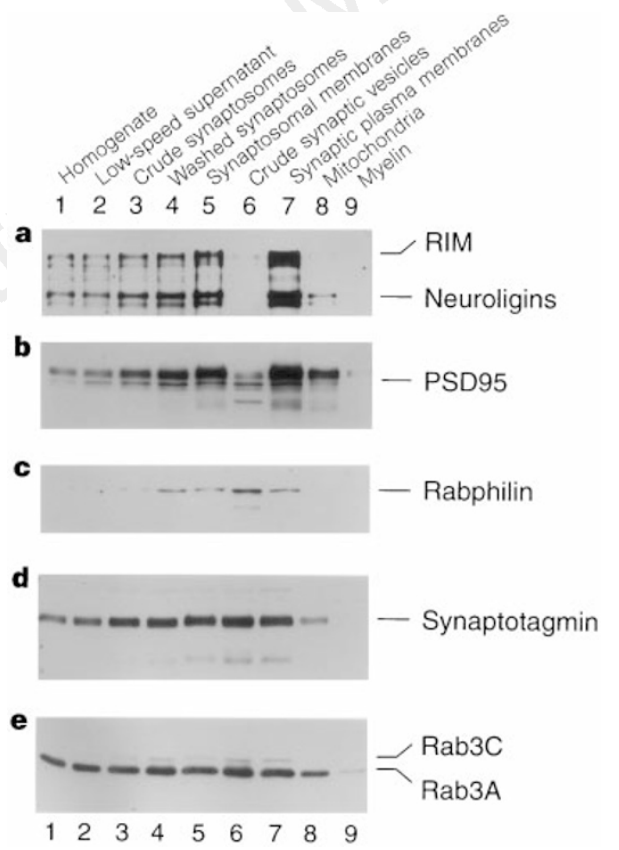

Figure 2 Localization of Rim to synaptic plasma membranes by subcellular fractionation. Rat brain homogenate (lane 1) was used to purify synaptosomes (lane 4), which were subfractionated into synaptic vesicles (Ine 6), synaptic plasma membranes (lane 7), mitochondria (lane 8) and myelin (lane 9). Equivalent amounts of protein from each fraction were analysed by immunoblotting with antibodies to the proteins indicated in five independent blots: $\mathbf{a}$, Rim/neuroligins; b, PSD95; c, rabphilin; d, synaptotagmin; e, Rab3A and Rab3C.
The N-terminal zinc-finger domain of Rim is followed by a highly charged sequence containing phosphorylation consensus sequences for cyclic AMP- and $\mathrm{Ca}^{2+} /$ calmodulin-dependent protein kinases, an alanine/proline-rich sequence, a PDZ domain, and two degenerate $\mathrm{C}_{2}$ domains, which are separated by alternatively spliced sequences. In other proteins, PDZ domains recruit proteins to intercellular junctions. For example, the postsynaptic density protein PSD95 is thought to localize $\mathrm{K}^{+}$channels, NMDA $(\mathrm{N}-$ methyl-D-aspartate) receptors and nitric oxide synthase to synaptic junctions, and $\mathrm{ZO}-1$ and $\mathrm{ZO}-2$ are thought to organize tight junctions (reviewed in ref. 19). The presence of a PDZ domain in Rim is surprising because no other known membrane transport protein contains a PDZ domain, and no protein described has both PDZ and $\mathrm{C}_{2}$ domains. Rabphilin and synaptotagmins are membrane transport proteins that contain $\mathrm{C}_{2}$ domains which bind $\mathrm{Ca}^{2+}$ by a defined consensus sequence ${ }^{15}$. In Rim, however, the $\mathrm{C}_{2}$ domain consensus sequence and their $\mathrm{Ca}^{2+}$-binding sites are mutated. Furthermore, rabphilin and synaptotagmins have a conserved Cterminal sequence following the $\mathrm{C}_{2}$ domains ${ }^{15}$ that is absent from Rim. Thus, although both Rim and rabphilin have $\mathrm{C}_{2}$ domains, those of Rim occur in a different domain context and are structurally distinct, setting Rim apart from the vesicular $C_{2}$ domain proteins rabphilin and synaptotagmins.

Rabphilin levels are decreased by $\sim 70 \%$ in Rab3A-knockout mice, probably because Rab3A recruits rabphilin to synaptic vesicles and mediates its transport from the cell body to synapses ${ }^{12}$. To test whether Rim exhibits a similar dependence on Rab3A, we measured Rim levels in Rab3A-knockout mice. No change in Rim was observed in Rab3A-knockout mice in spite of a decrease in rabphilin and the similar Rab3-binding properties of the two proteins (data not shown). This result raises the possibility that Rim may not only be structurally different from rabphilin, but may also be subject to a different intracellular targeting pathway.

We used subcellular fractionation to address this question. Preliminary experiments suggested that Rim is enriched in synaptosomes and that it is particulate (data not shown). We therefore subfractionated synaptosomes into synaptic plasma membranes, synaptic vesicles, and mitochondria. Immunoblotting showed Rim to be highly enriched in synaptic plasma membranes, together with PSD95 and neuroligins (Fig. 2). Rim was absent from mitochondria, myelin and synaptic vesicles, whereas most of the Rab3A and rabphilin was associated with synaptic vesicles. Rim was also not detectable in highly purified synaptic vesicles, which did, however, contain abundant amounts of Rab3A and rabphilin (data not shown). In addition to the vesicle fraction, Rab3A and other vesicle proteins were also enriched in synaptic plasma membranes because they contain tightly docked synaptic vesicles. Taken together, these data suggest that Rim is coenriched with the PDZ-domain protein PSD95 in synaptic junctions but is absent from synaptic vesicles.

The biochemical results raise the possibility that Rim as a Rab3 target may be localized to the presynaptic plasma membrane, the target of synaptic vesicles that carry Rab3. This localization would agree well with the presence of a PDZ domain in Rim, a domain that is normally found in junctional plasma-membrane proteins ${ }^{19}$. We tested this hypothesis by immunocytochemistry of nerve terminals using immunofluorescence staining and silver-enhanced immunogold labelling. Immunofluorescence in spinal-cord motor neurons revealed a punctate staining pattern for Rim, with abundant labelling of synapses on the cell bodies of the motor neurons (Fig. $3 \mathrm{~A}, \mathrm{a})$. Silver-enhanced immunogold labelling of the same synapses showed that Rim is exclusively presynaptic with no labelling outside nerve terminals. In the nerve terminals, we observed silver deposits close to the active zone but nowhere else; synaptic vesicles, the cytoplasm of the nerve terminals, and the plasma membrane outside the presynaptic active zone were not consistently labelled. (Fig. 3A,b).

Our data suggest that Rim may be specific for active zones in 

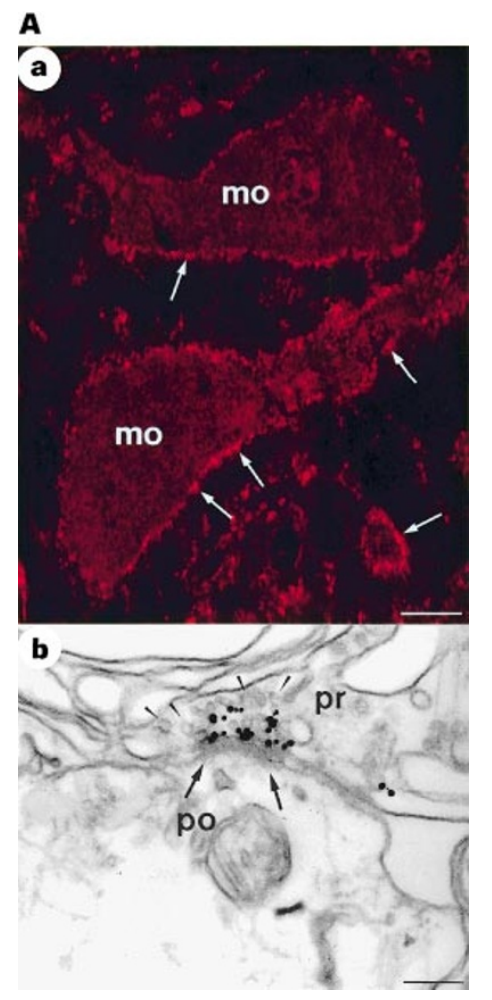

B

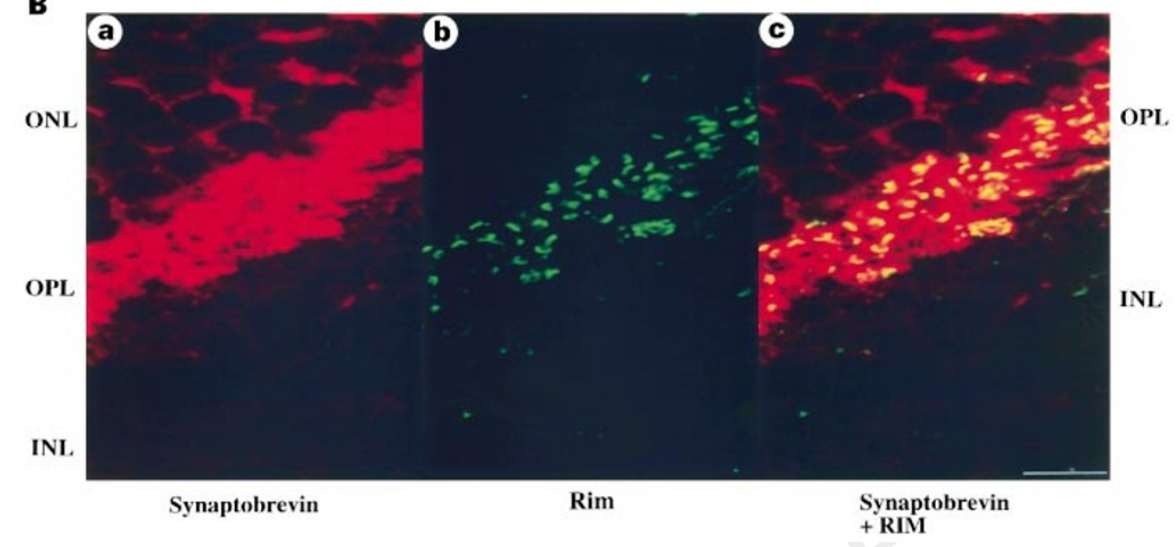

C
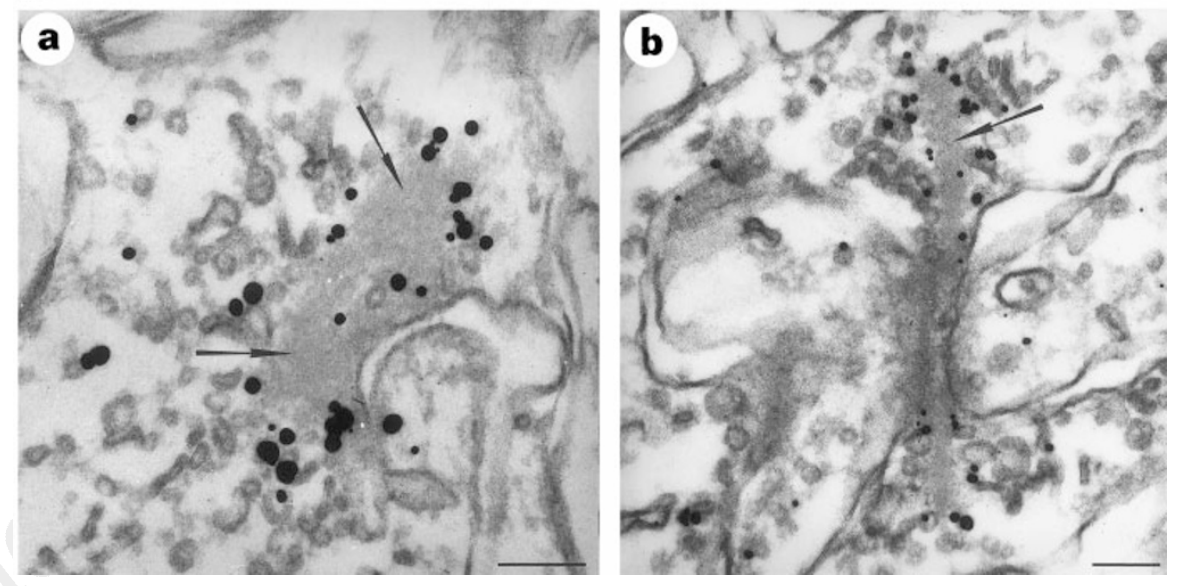

Figure 3 A, Localization of Rim in spinal-cord motor neurons. a, Confocal micrograph of rat spinal-cord crysostat section stained with Rim primary and Cy2conjugated secondary antibodies. Arrows point to synapses on motor-neuron cell bodies $(\mathrm{mo})$. Scale bar, $50 \mu \mathrm{m}$. b. Electron micrograph of a presynaptic terminal (pr) synapsing onto a postsynaptic neuron (po) stained for Rim by silverenhanced immunogold labelling. Signals appear as black deposits found only in presynaptic nerve terminals close to the active zone. Scale bar, $0.2 \mu \mathrm{m}$. B, Localization of synaptobrevin-2 and Rim in the outer plexiform layer of the retina by immunofluorescence microscopy. Confocal micrograph of a bovine retina cryostat section double-labelled with monoclonal antibodies to synaptobrevin-2 (a, red) and polyclonal antibodies to $\operatorname{Rim}$ (b, green). c, Images in $\mathbf{a}$ and $\mathbf{b}$ are merged, with areas positive for both antigens shown in yellow. Layers of the retina are identified on the left and right: ONL, outer nuclear layer; OPL, outer plexiform layer; INL, inner nuclear layer. Scale bar, $10 \mu \mathrm{m}$. C, Immunoelectron microscopy of Rim in photoreceptor synapses. Electron micrograph of retinal synapses labelled for Rim by silver-enhanced immunogold staining. Ribbons (arrows) are shown in profile (a) or cross-section (b). Labelling is enriched on the surface of the ribbons but absent from synaptic vesicles and the plasma membrane outside the ribbons. Scale bar, $0.1 \mu \mathrm{m}$. nerve terminals. However, the small size of active zones in conventional synapses and the limited spatial resolution of silver-enhanced immunogold labelling make it difficult to determine whether the label is directly associated with the active zone. To resolve this, we studied ribbon synapses of retinal photoreceptor cells that contain synaptic ribbons instead of active zones. Ribbons are relatively large structures attached to the presynaptic plasma membrane, and can be easily visualized. Ribbons appear to dock synaptic vesicles and prepare them for exocytosis, in a manner analogous to the active zone of conventional synapses ${ }^{20}$. Although ribbon synapses are structurally distinct from conventional synapses, they are probably similar mechanistically and contain the same synaptic proteins.

We performed double immunofluorescence labelling of retinae with antibodies to Rim and to the synaptic-vesicle protein synaptobrevin II (Fig. 3b). Both proteins were highly enriched in synapses but were distributed in strikingly different patterns. Synaptobrevin was present throughout the synaptic layer because it is localized in all synaptic vesicles of the entire nerve terminal. In contrast, Rim was found only in a small area within the synapses. The pattern of Rim immunofluorescence in photoreceptor nerve terminals sug- gests that its localization is restricted to ribbons. We confirmed this localization by immuno-electron microscopy and by biochemical isolation of ribbons. Silver-enhanced immunogold labelling revealed strong labelling of the surface of the entire synaptic ribbons (Fig. 3C). Synaptic vesicles or the adjacent plasma membranes, similar to conventional synapses, were largely unlabelled. Biochemical isolation of synaptic ribbons also demonstrated a high degree of enrichment of Rim with the detergent-insoluble ribbons (data not shown). Taken together, these data establish that Rim is present exclusively on ribbons in ribbon synapses and, to our knowledge, it is the first protein to be identified with such a localization.

By every indication, Rim should be involved in exocytosis. It is strategically localized to the active zone and to synaptic ribbons, and it specifically interacts with GTP-bound Rab3, which is localized to synaptic vesicles that dock to these structures. To confirm that Rim is involved in exocytosis, we investigated the effect of the N-terminal zinc-finger domain of Rim on the regulated secretion of growth hormone in transfected PC12 cells ${ }^{2}$. When we co-transfected human growth hormone with mutant inactive tetanus toxin as a control into PC cells, we observed efficient $\mathrm{Ca}^{2+}$-dependent growth-hormone 


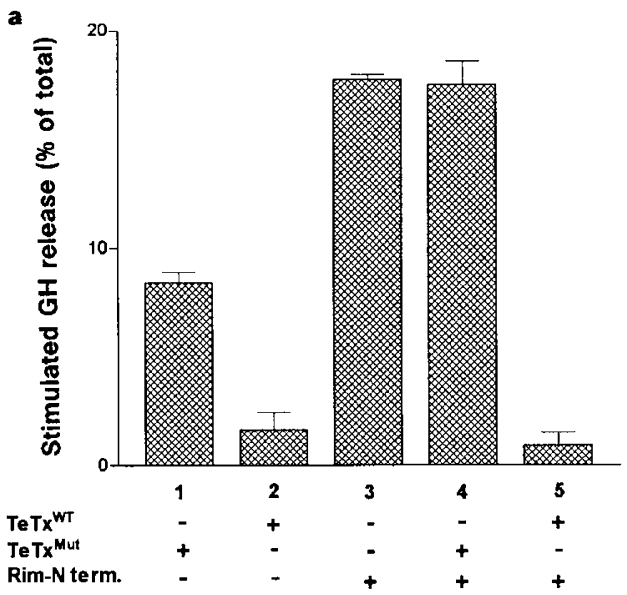

Figure 4 Rab3-dependent regulation of $\mathrm{Ca}^{2+}$-dependent secretion in transfected PC12 cells. PC12 cells were co-transfected with plasmids encoding human growth hormone $(\mathrm{GH})$ and the proteins indicated: $T e T x^{W T}$, light chain of wild-type tetanus toxin; TeTx ${ }^{\text {Mut }}$, light chain of mutant inactive tetanus toxin ${ }^{28}$; Rim-N term., N-terminal domains of Rim; LDLR, LDL receptors. Graphs show K ${ }^{+}$-stimulated

secretion triggered by membrane depolarization (Fig. 4a). In contrast, when we co-transfected wild-type tetanus toxin, $\mathrm{Ca}^{2+}$-dependent secretion was largely suppressed. This confirms that the secretion observed is vesicular.

Co-transfection of the N-terminal domain of Rim with growth hormone, with or without the mutant tetanus toxin, resulted in a large increase in $\mathrm{Ca}^{2+}$-dependent secretion that was not observed with any other co-transfected protein (Fig. 4a). The increase in secretion caused by Rim transfection was fully suppressed by wildtype tetanus toxin, showing that it is also due to vesicular exocytosis. Co-transfection of wild-type Rab4A with growth hormone, however, leads to a mild inhibition of triggered secretion ${ }^{2}$ (Fig. 4b). The Rab3A inhibition and the Rim enhancement neutralize each other if both proteins are co-transfected. These data suggest that Rim has a functional role in secretion, although they do not establish whether Rim acts directly or indirectly. In agreement with the enhanced neurotransmitter release in the absence of Rab3A in hippocampal synapses ${ }^{4}$, our results indicate that interference with Rab3 function by expression of a truncated Rim protein promotes vesicular secretion.

Rab3A regulates synaptic-vesicle exocytosis by limiting the extent of $\mathrm{Ca}^{2+}$-triggered membrane fusion ${ }^{4}$. This regulation is physiologically important for mossy fibre LTP, and possibly other forms of synaptic plasticity ${ }^{5}$. Rim is a candidate effector protein for Rab3 that may mediate the actions of Rab3 in membrane fusion. In Rim and rabphilin, a previously described putative Rab3 effector ${ }^{11,12}$, Rab3 may have two distinct effector proteins. Although both of these effectors interact with Rab3 through related zinc-finger sequences, they are composed of different domains and localized to distinct subcellular compartments. Thus Rab3, and possibly other Rab proteins, could have multiple downstream functions mediated by diverse effectors. Rab3 and rabphilin are colocalized on synaptic vesicles $^{12,13}$. In contrast, Rim is only found on presynaptic active zones and synaptic ribbons, and is the first protein known to have this restricted localization. Other proteins of the synaptic plasma membrane, such as syntaxin and munc18-1, are distributed all over the plasma membrane, without enrichment in active zones. Because Rab3 is on synaptic vesicles, Rim can only bind to Rab3 when synaptic vesicles carrying GTP-Rab3 move to the active zone. As a consequence, the Rim-Rab3 complex forms only during or after docking of synaptic vesicles. The localization of Rim positions it for a role in synaptic-vesicle docking and fusion, in contrast to the b

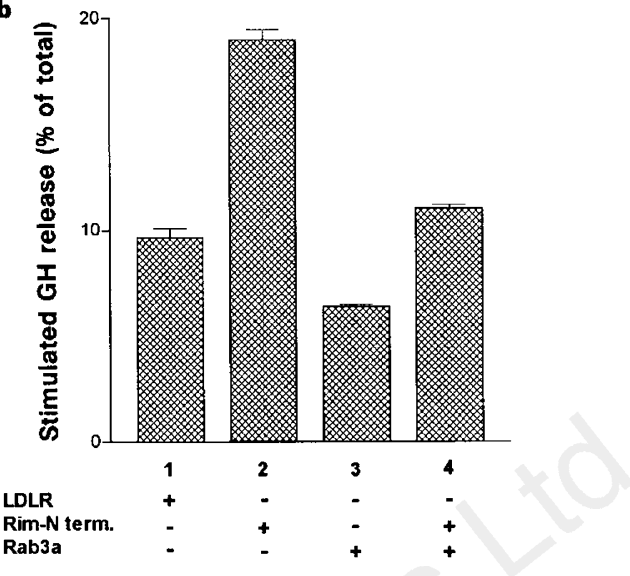

release of growth hormone plotted as a percentage of total growth hormone expressed. Basal release was $6.5-8.5 \%$ of total, and did not change significantly as a function of transfection, except for wild-type tetanus toxin, which also decreased basal release. The increase in stimulated exocytosis induced by Rim remains sensitive to tetanus toxin and is reversed by Rab3A expression.

localization of rabphilin, which is present on free vesicles long before they reach the active zone ${ }^{12}$. One possible model for Rab3 function is that the Rab3-Rim complex might serve as a clamp for $\mathrm{Ca}^{2+}$-dependent exocytosis. Stochastic or regulated inactivation of this clamp by GTP hydrolysis or protein phosphorylation would then regulate the availability of vesicles for fusion, thereby determining how many vesicles fuse. Genetic and biochemical tests of this model are in progress.

\section{Methods}

Molecular biology. Yeast-two hybrid bait vectors were constructed by standard techniques $^{21}$ in pLexN using full-length Rab sequences with the indicated mutations. Yeast two-hybrid screens of a rat brain cDNA library in pVP16-3 were performed and evaluated as described ${ }^{14,22}$. Two independent Rim prey clones encoding residues 1-345 (pPreyRim-100) and 11-399 (pPreyRim-52) were isolated. Liquid $\beta$-galactosidase assays were normalized for protein content $^{22}$. A rat brain cDNA library in $\lambda$ ZAPII was screened by standard methods ${ }^{21}$ using the Rim prey clone as a probe. Multiple overlapping clones covering the entire coding were sequenced to assemble the full-length sequence (GenBank accession number: AF007836). Rim-GST fusion protein vectors were obtained by cloning the EcoRI fragment from pPreyRim-52 into pGEX$\mathrm{KG}^{23}$ (pGexRIM52; N-terminal zinc-finger construct) or the 0.84-kilobase SmaI-PvuII fragment into the SmaI site (pGexRim-PDZ; this encodes residues 492-772).

Sequence analysis. Initial databank searches using BLAST software identified the domains in Rim (N-terminal zinc-finger, PDZ domain, and $\mathrm{C}_{2}$ domains). The complete Rim C. elegans sequence was assembled from two cosmid sequences (T10A3 and K03A1; acc. nos U41035 and U41625, respectively). In order to define the relation of the Rim zinc-finger to other databank zincfingers, we applied the generalized profile method ${ }^{24}$. A profile was constructed from a weighted multiple alignment of the zinc-finger regions from rat and $C$. elegans Rim and rabphilin using the BLOSUM45 substitution matrix ${ }^{25}$ with a gap-creation penalty of 2.1 and gap-extension penalty of 0.2 . Statistical significance of profile-matching scores was derived from the analysis of the score distribution of a locally shuffled database ${ }^{26}$. Significant matches $(P<0.08)$ were incorporated into subsequent rounds of profile construction for iterative profile refinement. The initial profile search found significant matches to the zinc-finger regions of the nematode open reading frames C33D9.1 $(P<0.06)$ and ZK632.12 $(P<0.08)$. The two sequences were considered related to the Rim zinc-finger domain family and incorporated into the alignment for the next round of profile refinement. Three more profile refinement cycles, accepting only proteins with error probabilities of $P<0.01$, 
resulted in the protein family shown in Fig. 1c. The highest-scoring non-related sequences after those shown consisted of trithorax family members that reached error probabilities of $P>0.5$ in all of the profile iterations.

Immunocytochemistry. Antibodies were raised in rabbits against the purified GST fusion proteins encoded by pGEX-RIM-52 and pGEX-Rim-PDZ. Double and single immunofluorescence labelling of cryostat sections from rat spinal cord and bovine retinae was performed ${ }^{27}$ with two independent polyclonal Rim antibodies and multiple monoclonal antibodies to synaptic vesicle proteins. Staining was visualized by Cy2- and Cy3-conjugated secondary antibodies and viewed in a BioRad MRC1024 confocal microscope. Immuno-electron microscopy was performed by a pre-embedding protocol with silver enhancement $t^{27}$. Controls for all immunocytochemistry experiments included the use of two independent antibodies, control stains with other antibodies, and experiments in which the first antibody was omitted.

PC12 cell transfections. PC12 cells (ATCC) were plated in collagen-coated 6well dishes with $10^{6}$ cells per well. Cells were transfected on day 1 with $0.2 \mu \mathrm{g}$ of Qiagen-purified pCMV5-hGH encoding human growth hormone and $1 \mu \mathrm{g}$ of the indicated expression plasmids using Lipofectamine (Life Technologies). Expression plasmids encoded the light chains of wild-type and mutant tetanus toxin in pCMV5 (ref. 28), LDL receptor and Rab3A in pCMV5, and residues $1-399$ of Rim in pME18sf(-). On day 3, cells were collected, washed, and split into two portions, one of which was incubated for $20 \mathrm{~min}$ at $37^{\circ} \mathrm{C}$ in control buffer (in $\mathrm{mM})\left(145 \mathrm{NaCl}, 5.6 \mathrm{KCl}, 2.2 \mathrm{CaCl}_{2}, 0.5 \mathrm{MgCl}_{2}, 5.6\right.$ glucose, 0.5 ascorbate, 20 HEPES-NaOH, pH 7.4) and the other was incubated in the same buffer containing $56 \mathrm{KCl}$ and $95 \mathrm{NaCl}$. After incubation, growth hormone in the medium and the cells was determined by radioimmunoassay (Nichols Institute). Secretion was calculated as the percentage growth hormone released as a function of stimulation. All experiments were done in triplicate at least three times.

Rim affinity chromatography. Glutathione-agarose columns without protein, with GST-Rim fusion protein encoded by pGEX-Rim-52, or with various control GST fusion proteins, were reacted with total rat brain homogenate prepared in $0.5 \%$ Triton X-100, $1 \mathrm{mM}$ EDTA, $0.1 \mathrm{M} \mathrm{NaCl}, 0.1 \mathrm{gl}^{-1}$ PMSF, and $50 \mathrm{mM}$ HEPES- $\mathrm{NaOH}, \mathrm{pH} 7.4$, with either $0.5 \mathrm{mM}$ GDP- $\beta \mathrm{S}$ or GTP- $\gamma \mathrm{S}$ at $4{ }^{\circ} \mathrm{C}$ overnight. Samples were washed 5 times in the same buffer without nucleotides before analysis by SDS-PAGE and immunoblotting.

Other procedures. RNA blotting experiments were done using multiple tissue blots (Clontech). SDS-PAGE and immunoblotting were performed using standard procedures and antibodies described previously ${ }^{1,12,28,29}$. Signals were detected by ECL and quantified by ${ }^{125} \mathrm{I}$-labelled secondary antibodies. Protein assays were performed with the BioRad kit. Subcellular fractionations were performed as described ${ }^{29}$ and verified by immunoblotting against a series of synaptic-vesicle, plasma-membrane and cytosolic antigens.

Received 19 February; accepted 22 May 1997

1. Geppert, M. et al. The role of Rab3A in neurotransmitter release. Nature 369, 493-497 (1994).

2. Holz, R. W., Brondyk, W. H., Senter, R. A., Kuizon, L. \& Macara, I. G. Evidence for the involvement of Rab3A in $\mathrm{Ca}^{2+}$-dependent exocytosis from adrenal chromaffin cells. J. Biol. Chem. 269, 10229-10234 (1994)

3. Johannes, L. et al. The GTPase Rab3a negatively controls calcium-dependent exocytosis in neuroendrocrine cels. EMBO J. 13, 2029-2037 (1994).

4. Geppert, M., Goda, Y., Stevens, C. F. \& Südhof, T. C. Rab3A regulates a late step in synaptic vesicle fusion. Nature 387, 810-814 (1997)

. Castillo, P. E., Janz, R., Südhof, T. C., Tzounopoulos, T., Malenka, R. C. \& Nicoll, R. A. Rab3A is essential for mossy fibre long-term potentiation in the hippocampus. Nature 388, 590-593 (1997)

6. Burstein, E. S., Brondyk, W. H., Macara, I. G., Kaibuchi, K. \& Takai, Y. Regulation of the GTPase cycle of the neuronally expressed Ras-like GTP-bindign protein Rab3A. J. Biol. Chem. 268, 22247-22250 (1993).

. Fischer von Mollard, G., Stahl, B., Khokhlatchev, A., Südhof, T. C. \& Jahn, R. Rab3C is a synaptic vesicle protein that dissociates from synaptic vesicles after stimulation of exocytosis. J. Biol. Chem. 269, 10971-10974 (1994).

8. Südhof, T. C. Function of Rab3A GDP/GTP exchange. Neuron 18, 519-522 (1997).

9. Bourne, H. R., Sanders, D. A. \& McCormick, F. The GTPase superfamily: a conserved switch for diverse cel functions. Nature 348, 125-132 (1990).

10. Nuoffer, C. \& Balch, W. E. GTPases: multifunctional molecular switches regulating vesicular traffic. Аnnu. Rev. Biochem. 63, 949-990 (1994).

11. Shirataki, H. et al. Rabphilin-3A, a putative target protein for smg p25A/rab3A p25 small GTPbinding protein related to synaptotagmin. Mol. Cell. Biol. 13, 2061-2068 (1993).

12. $\mathrm{Li}$, C. et al. Synaptic targeting of rabphilin-3A, a synaptic vesicle $\mathrm{Ca}^{2+} /$ phospholipid-binding protein, depends on rab3A/3C. Neuron 13, 885-898 (1994).

13. Stahl, B., Chou, J. H., Li, C., Südhof, T. C. \& Jahn, R. Rab3 reversibly recruits rabphilin to synaptic vesicles by a mechanism analogous to raf recruitment by ras. EMBO J. 15, 1799-1809 (1996).

14. Vojtek, A. B., Hollenberg, S. M. \& Cooper, J. A. Mammalian ras interacts directly with the serin/ threonine kinase raf. Cell 74, 205-214 (1993).

15. Südhof, T. C. \& Rizo, J. Synaptotagmins: $\mathrm{C}_{2}$-domain proteins that regulate membrane traffic. Neuron 17, 379-388 (1996)
16. Weisman, L. S. \& Wickner, W. Molecular characterization of VACl, a gene required for vacuole inheritance and vacuole protein sorting. J. Biol. Chem. 267, 618-623 (1992).

17. Yamamoto, A. et al. Novel PI(4)P 5-kinase homologue, Fablp, essential for normal vacuole function and morphology in yeast. Mol. Biol. Cell 6, 525-539 (1995).

18. Bean, A. J., Seifert, R., Chen, Y. A., Sacks, R. \& Scheller, R. H. Hrs-2 is an ATPase implicated in $\mathrm{Ca}^{2+}$ regulated secretion. Nature 385, 826-829 (1997).

19. Sheng, M. PDZs and receptor/channel clustering: rounding up the latest suspects. Neuron 17, 575578 (1996).

20. Dowling, J. E. The Retina. An Approachable Part of the Brain (Belknap, Cambridge, MA, 1987).

21. Sambrook, J., Fritsch, E. F. \& Maniatis, T. Molecular Cloning: A Laboratory Manual (Cold Spring Harbor Laboratory Press, New York, 1989).

22. Hata, Y. \& Südhof, T. C. A novel ubiquitous form of muncl8 interacts with multiple syntaxins. J. Biol. Chem. 270, 13022-13028 (1991).

23. Guan, K. L. \& Dixon, J. E. Eukaryotic proteins expressed in Escherischia coli: an improved thrombin cleavage and purification procedure of fusion proteins with glutathione S-transferase. Anal. Biochem. 192, 262-267 (1991)

24. Bucher, P., Karplus, K., Moeri, N. \& Hofmann, K. A flexible motif search technique based on generalized profiles. Comput. Chem. 20, 3-23 (1996).

25. Henikoff, S. \& Henikoff, J. G. Amino acid substitution matrices from protein blocks. Proc. Natl Acad. USA 89, 10915-10919 (1992)

26. Hofmann, K. \& Bucher, P. The FHA domain: a putative nuclear signalling domain found in protein kinases and transcription factors. Trends Biochem. Sci. 20, 347-349 (1995).

27. Schmitz, F., Bechmann, M. \& Drenckhahn, D. Purification of synaptic ribbons, structural components of the photoreceptor active zone complex. J. Neurosci. 15, 7109-7116 (1996).

28. McMahon, H. et al. Cellubrevin: a ubiquitous tetanus-toxin substrate homologous to a putative synaptic vesicle fusion protein. Nature 364, 346-349 (1993).

29. Ichtchenko, K. et al. Neuroligin 1: A splice-site specific ligand for $\beta$-neurexins. Cell 81, 435-443 (1995)

30. Matsui, Y. et al. Nucleotide and deduced amino acid sequences of a GTP-binding protein family with molecular weights of 25,000 from bovine brain. J. Biol. Chem. 263, 11071-11074 (1988)

Acknowledgements. We thank R. Janz, R. Jahn, M. Zerial and S. Butz for reagents, and J. L. Goldstein and M. S. Brown for advice and support. This work was partially supported by a grant from the HFSP.

Correspondence and requests for materials should be addressed to T.C.S. (e-mail: tsudho@mednet. swmed.edu).

\section{Chromatin-remodelling factor CHRAC contains the ATPases ISWI and topoisomerase II}

\section{Patrick D. Varga-Weisz, Matthias Wilm, Edgar Bonte, Katia Dumas, Matthias Mann \& Peter B. Becker}

European Molecular Biology Laboratory, Meyerhofstrasse 1, 69117 Heidelberg, Germany

Repressive chromatin structures need to be unravelled to allow DNA-binding proteins access to their target sequences. This de-repression constitutes an important point at which transcription and presumably other nuclear processes can be regulated ${ }^{1,2}$. Energy-consuming enzyme complexes that facilitate the interaction of transcription factors with chromatin by modifying nucleosome structure are involved in this regulation ${ }^{3-5}$. One such factor, nucleosome-remodelling factor (NURF), has been isolated from Drosophila embryo extracts ${ }^{4,6,7}$. We have now identified a chromatin-accessibility complex (CHRAC) which uses energy to increase the general accessibility of DNA in chromatin. However, unlike other known chromatin remodelling factors, CHRAC can also function during chromatin assembly: it uses ATP to convert irregular chromatin into a regular array of nucleosomes with even spacing. CHRAC combines enzymes that modulate nucleosome structure and DNA topology. Using mass spectrometry, we identified two of the five CHRAC subunits as the ATPase ISWI, which is also part of $\mathrm{NURF}^{6,8}$, and topoisomerase II. The presence of ISWI in different contexts suggests that chromatin remodelling machines have a modular nature and that ISWI has a central role in different chromatin remodelling reactions.

Chromatin reconstituted in the cell-free assembly system from Drosophila embryos ${ }^{9,10}$ is maintained in a dynamic state characterized by increased nucleosome mobility and overall DNA accessibility in the presence of $\mathrm{ATP}^{11}$. Using ATP-dependent endonuclease cleavage of chromatin to assay for DNA accessibility ${ }^{11}$, we purified and characterized a new type of chromatin remodelling 